\title{
AVALIAÇÃO DO VOLUME NECESSÁRIO DE DESCARTE DE ÁGUA DE CHUVA ESCOADA SOBRE COBERTURAS DE DIFERENTES MATERIAIS
}

\section{ASSESSMENT OF FIRST FLUSH WATER DIVERTER REQUIRED OF RAINWATER COLLECTED AFTER THE FLOW ON DIFFERENT TYPES OF ROOFING MATERIALS}

\author{
Bárbara Cristina Castro de Melo Rocha ${ }^{1}$, Ricardo Prado Abreu Reis ${ }^{2}$, \\ José Vicente Granato de Araújo ${ }^{3}$
}

Recebido em 26 de junho de 2011; recebido para revisão em 28 de junho de 2011; aceito em 10 de agosto de 2011; disponivel on-line em 28 de setembro de 2011.

\author{
PALAVRAS CHAVES: \\ Aproveitamento de água \\ de chuva; \\ Descarte de água de \\ chuva; \\ Sistemas prediais de água \\ pluvial.
}

\section{KEYWORDS:}

First Flush Rainwater Diverter;

Rainwater use;

Rainwater Harvesting.
RESUMO: A escassez de água se tornou um dos grandes problemas mundiais. Buscando contribuir para a conservação de água dentro do meio urbano, novas formas de concepções mais sustentáveis de sistemas hidráulicos prediais vêm sendo desenvolvidas. Esta pesquisa tem como objetivo, avaliar o volume de água de chuva que deve ser descartada em função do tempo de estiagem, em um sistema de captação montado em três diferentes tipos de cobertura na Escola de Engenharia Civil da Universidade Federal de Goiás - EEC-UFG. Os resultados obtidos por meio das análises físico-químicas e bacteriológicas demonstram que, para as condições estudadas, devem ser descartadas aproximadamente $150 \mathrm{~L}$ de água do escoamento inicial para que a mesma atenda aos critérios estabelecidos pela NBR 15.527 ABNT (2007). A avaliação da qualidade da água de chuva coletada nos três telhados, após o descarte, também, possibilitou verificar que há necessidade de tratamento anteriormente a sua utilização.

ABSTRACT: Water scarceness has become a major problem worldwide, which is evidencing to the need for studies of new methods and techniques of water conservation, aiming to produce effective solutions to minimize this problem within building environments. Among the possible water conservation technologies in buildings, rainwater harvesting can be a powerful alternative. The objective of this study is to evaluate the disposal of rainwater collected in three roofs made by different types of materials such as: metal, asbestos cement and clay, located in the area of the School of Civil Engineering at the Federal University of Goiás. After monitoring the volume of discharge correlated with the evaluation of the quality of rainwater collected in each type of roof, and with the rain water collected directly from the atmosphere, the processes were evaluated based on the observed parameters and on the criteria established by the NBR 15.527 (ABNT, 2007). It was observed that the process of disposal of rain water is essential for obtaining water with better quality in these systems. It was also noted that the disposal based on time of rainfall was not sufficient to obtain rainwater with assured quality. Among the evaluated roofs, the metal tile proved to produce the best water quality after discarding the first $150 \mathrm{~L}$ collected (corresponding to a $2 \mathrm{~mm}$ of rainfall over the areas of contribution studied). Moreover, the volume of disposal corresponding to the $2 \mathrm{~mm}$ of accumulated rainfall, as suggested by NBR 15.527, were not sufficient to ensure that the rainwater collected can be used without risk to users and water installations, which demands at least a simplified water treatment. 
* Contato com os autores:

${ }^{1}$ e-mail : barbaracristinarocha@gmail.com (B. C. C. M. Rocha)

Arquiteta, Mestre em Engenharia Ambiental, Professora do IF-GO.

22e-mail : rpareis@gmail.com (R.P.A. Reis)

Professor MSc. da Escola de Engenharia Civil da Universidade Federal de Goiás

3e-mail : jvgranato@yahoo.com.br (J. V. G. Araújo)

Professor PhD. da Escola de Engenharia Civil da Universidade Federal de Goiás

\section{INTRODUÇÃO}

O aumento da demanda de água associado a sua degradação cada vez mais intensa, vem impossibilitando sua renovação natural em muitas regiões do planeta. Dentre os impactos causados por essa ação antrópica, podem ser citados o desequilíbrio do ciclo hidrológico e o fenômeno de estresse hídrico. O crescimento populacional e sua concentração em centros urbanos, juntamente com a necessidade de aumento da produção agrícola e do desenvolvimento industrial contribuem para o aumento da demanda por água e, também, para a degradação de sua qualidade.

Segundo dados publicados no World Economic Forum (McKINSEY, 2009) está previsto um grande aumento na demanda por água nas áreas urbanas projetado para o ano de 2030. Caso esta projeção de aumento de demanda de água venha se concretizar, ela ocasionará o agravamento ainda maior da escassez de água em nível mundial. Conforme demonstra o gráfico da Figura 1, a projeção de aumento da demanda por água na América do Sul e América Central, para o ano de 2030, somando os usos domésticos e industriais, é de $97 \%$. Índices similares são previstos para praticamente todas as regiões do planeta. Esta projeção sinaliza a necessidade do desenvolvimento de mais pesquisas, consolidação e aplicação de técnicas voltadas para a conservação e utilização racional da água no ambiente construído.

Dando enfoque aos índices de abastecimento urbano de água potável, atualmente no estado de Goiás Brasil, região onde foi realizado este estudo, a Saneamento de Goiás S/A - SANEAGO, concessionária pública, responsável pela captação, tratamento e distribuição de água e coleta de esgoto para a população urbana, atende aproximadamente $85 \%$ da população urbana com água tratada em 223 municípios e 47 localidades do estado de Goiás (SANEAGO, 2009). Em Goiânia-GO, o faturamento devido ao consumo de água varia muito entre as categorias de abastecimento, como demonstrado no gráfico da Figura 2, onde a categoria residencial apresenta um consumo de $83,3 \%$, percentual este considerado elevado em comparação com as outras categorias.

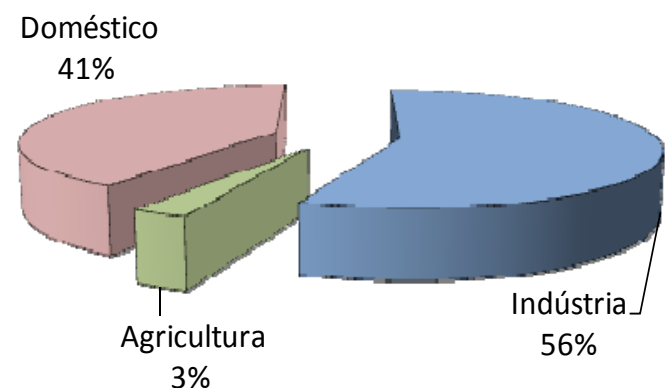

Figura 1: Aumento da demanda por água na América do Sul e Central até 2030 . Fonte: McKinsey (2009).

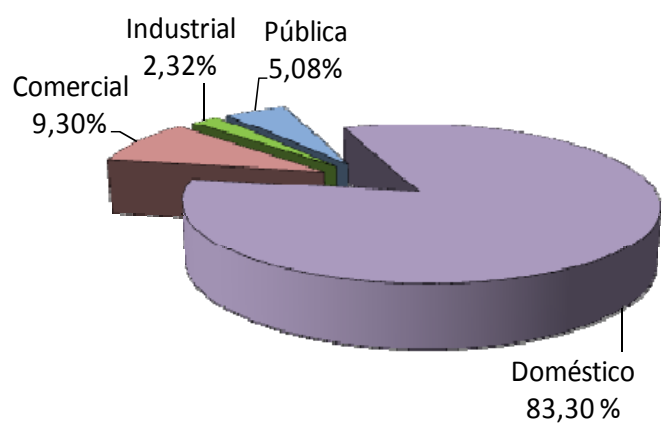

Figura 2: Indicadores de consumo de água faturada por tipo de consumo. Fonte: SANEAGO (2009).

Considerando-se a necessidade de se promover a conservação de água no meio urbano, o aproveitamento de águas de chuva, seria uma alternativa de abastecimento doméstico para os usos que não necessitam atender aos rigorosos padrões de potabilidade de água, tais como: descarga de bacias sanitárias, limpeza de pisos, rega de áreas verdes, lavagem de veículos e roupas e uso ornamental.

A implantação do sistema de aproveitamento de água de chuva para consumo humano, entretanto, tem-se tornado uma prática, nem sempre correta, em vários municípios brasileiros. A falta de critérios para a implantação destes sistemas culmina com a possibilidade da utilização de água com qualidade inadequada mesmo para o consumo não potável, colocando em risco a saúde pública.

A necessidade de conhecimento técnico sobre a coleta e avaliação de águas de chuva para posterior aproveitamento é fundamental, pois as águas carreiam das superfícies de escoamento e da própria atmosfera, poluentes que podem prejudicar a saúde do ser humano e degradar os sistemas prediais hidráulicos e sanitários. A avaliação do volume de água que deve ser descartada para que as águas coletadas possuam qualidade satisfatória para consumo é um dos pontos mais importantes na implantação de sistemas de aproveitamento de águas de chuva. 
Com vista nos problemas ressaltados anteriormente, o objetivo deste trabalho consiste em avaliar o desempenho do sistema de descarte para águas de chuva coletadas de coberturas de diferentes materiais (telhas metálicas, telhas de cimento amianto e telhas cerâmicas), por meio de análises qualitativas e quantitativas, visando à concepção de sistemas prediais de aproveitamento de água de chuva.

Para tanto foi analisada a correlação existente entre a qualidade da água captada em função do tempo de estiagem que precedeu cada coleta. Posteriormente foram comparados os resultados obtidos das amostras coletadas de cada tipo de cobertura em função do volume descartado, com os padrões estabelecidos pela NBR 15.527 (ABNT, 2007).

\section{METODOLOGIA}

Como processo metodológico, inicialmente foram escolhidas edificações para a realização do estudo experimental dos sistemas de coleta e descarte de água de chuva. As coberturas utilizadas para a realização deste trabalho encontram-se localizados em edificações situadas no pátio interno da Escola de Engenharia Civil da Universidade Federal de Goiás (EEC-UFG), na cidade de Goiânia-GO, sendo próximas uma das outras num raio máximo de afastamento de 20 metros. Assim, podese dizer que as águas de chuva captadas nos três pontos de coleta possuíam as mesmas características antes de chegar às coberturas, não sofrendo interferências de diferentes intensidades, duração e frequência de chuva ou presença de diferentes tipos de vegetação no entorno, ou de diferentes tipos de poluentes trazidos pelos ventos.

Para se obter a mesma área de contribuição nas três coberturas foram colocadas sob os beirais, calhas de zinco com diferentes medidas de comprimento para captar a água de chuva escoada, determinando uma área de captação de $75,80 \mathrm{~m}^{2}$ por cobertura estudada.

Foram selecionados os seguintes parâmetros para o estudo da qualidade das águas: turbidez, cor aparente, $\mathrm{pH}$, condutividade, sólidos dissolvidos, sólidos totais, alcalinidade, dureza, ferro, coliformes totais e E. coli. As análises dos parâmetros estabelecidos foram realizadas pelos laboratórios da SANEAGO localizados na ETA Jaime Câmara e na ETE Dr. Hélio Seixo de Brito, de acordo com as recomendações do "Standard Methods for Examination of Water and Wastewater"(APHA et al., 2004).

Nesta pesquisa, foram avaliados três tipos de coberturas, cada uma constituída de um tipo de material diferente: telhas trapezoidais com núcleo de poliuretano expandido, formando um conjunto rígido, conhecido como "sanduíche", pintadas pelo sistema Coil Coating da CSN, conhecido como "sanduíche", pintadas pelo sistema Coil Coating da CSN, um sistema de multicamadas com resina à base de poliéster, telhas de cimento amianto tipo ondulada e telhas de barro tipo plan.

As coberturas, existentes há mais de cinco anos no local, foram construídas de acordo com os critérios do fabricante de cada tipo de telha, critérios estes que atualmente ainda estão sendo utilizados no mercado. Para otimizar a coleta de água e permitir o seu armazenamento como amostras ao longo da precipitação, foi idealizado e montado um dispositivo composto de tubos, conexões, filtros e galões. Este dispositivo foi executado sob cada cobertura estudada permitindo a coleta de amostras das águas precipitadas em cada cobertura ao longo do mesmo evento de precipitação, com o enchimento dos galões de cada sistema.

A Figura 3 ilustra a configuração do sistema de coleta e armazenamento das águas precipitadas sobre a cobertura de cimento amianto.

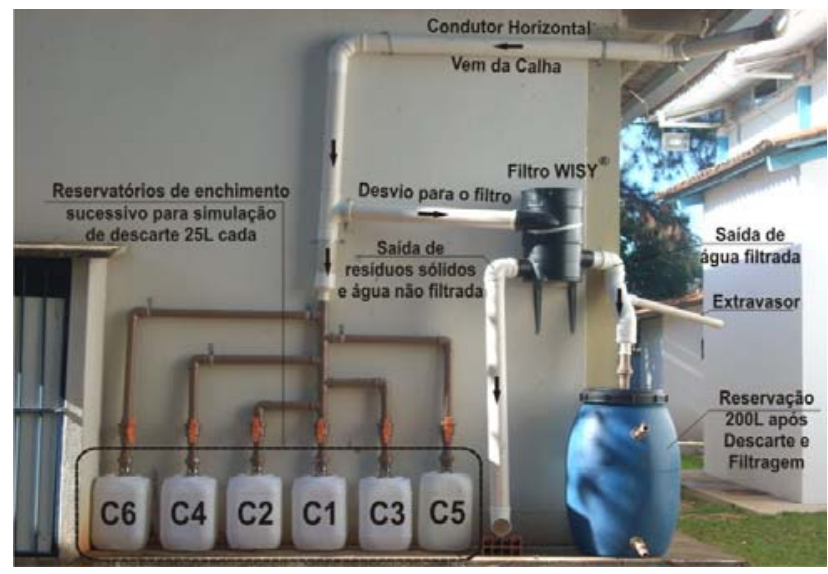

Figura 3: Sistema de coleta, descarte e armazenamento de água de chuva.

Como era o objetivo a avaliação da qualidade da água após $2 \mathrm{~mm}$ de precipitação acumulada, considerou-se avaliar os $150 \mathrm{~L}$ de água descartada, correspondentes aos $2 \mathrm{~mm}$ de chuva sobre a área de captação do experimento em cada cobertura. Este volume foi então dividido em seis galões provisórios de $25 \mathrm{~L}$ cada, conforme identificados na Figura 3. A água captada pelas calhas de zinco, em cada tipo de cobertura, escoava pelos condutores verticais e era armazenada temporariamente nestes recipientes que foram numerados de 1 a 6 . O preenchimento ocorria na ordem sequencial da numeração passando automaticamente para o próximo após cada um dos galões serem totalmente preenchidos. Após o preenchimento dos seis galões de armazenamento provisório, a água de chuva era direcionada ao filtro de sólidos grosseiros da Wisy, 
WWF 150, para posterior armazenamento nas bombonas de 200 Litros apoiadas sobre o solo. A água não filtrada é direcionada automaticamente ao descarte.

As amostras a serem enviadas aos laboratórios de análise de qualidade de água eram coletas em cada um dos galões de armazenamento provisório, após os mesmos serem desconectados das tubulações de descida e homogeneizados e, também, em dois pontos da bombona de 200 litros, sendo os pontos de coleta situados a $25 \mathrm{~cm}$ da borda superior e a $25 \mathrm{~cm}$ da borda inferior da mesma.

\section{RESULTADOS E DISCUSSÃO}

\subsection{Coletas}

O experimento iniciou-se em setembro de 2009 tendo estendido até fevereiro de 2010 com a coleta de 10 amostras de água de chuva escoadas de cada um dos três diferentes tipos de cobertura. As primeiras chuvas ocorreram com frequência baixa, como é característico do início do período chuvoso da cidade de Goiânia. A primeira coleta ocorreu após seis eventos de precipitação e, segundo os dados obtidos do Sistema de Meteorologia e Hidrologia do Estado de Goiás (SIMEHGO), da Secretaria de Ciência e Tecnologia e do pluviógrafo localizado no pátio interno da EEC-UFG, as chuvas ocorridas na cidade mantiveram a tendência do estado, apresentando um período chuvoso entre os meses de setembro a maio. Foram observados os períodos de estiagem ocorridos antes de cada coleta para posterior análise da influência deste fator na qualidade da água de chuva coletada, como apresentado na Tabela 1.

\begin{tabular}{|c|c|c|c|c|c|c|c|c|c|c|}
\hline COLETAS & 1 & 2 & 3 & 4 & 5 & 6 & 7 & 8 & 9 & 10 \\
\hline \multirow{2}{*}{$\begin{array}{l}\text { Data da coleta } \\
\text { (dia/mês) }\end{array}$} & \multicolumn{7}{|c|}{ ANO 2009} & \multicolumn{3}{|c|}{ ANO 2010} \\
\hline & $20 / 09$ & $30 / 09$ & $18 / 10$ & $9 / 11$ & $19 / 11$ & $6 / 12$ & $15 / 12$ & $7 / 01$ & $21 / 01$ & $10 / 01$ \\
\hline $\begin{array}{l}\text { Precipitação } \\
(\mathrm{mm} / \mathrm{h})\end{array}$ & 19,8 & 11 & 0,4 & 6,2 & 17,2 & 31 & 7,8 & 10,20 & 8,3 & 4,0 \\
\hline $\begin{array}{l}\text { Número de dias } \\
\text { sem precipitação } \\
\text { antes da coleta }\end{array}$ & 8 & 1 & 12 & 0 & 5 & 0 & 0 & 0 & 6 & 13 \\
\hline
\end{tabular}

\subsection{Parâmetros Avaliados}

\subsubsection{Turbidez e cor aparente}

Durante a ocorrência dos eventos de precipitação, a intensidade da mesma aumentou ou diminuiu em intervalos pequenos e dessa forma as curvas de decaimento da turbidez e cor aparente não se apresentaram constantes, ocorrendo variações nos valores dos resultados das análises das águas escoadas das coberturas e coletadas nos galões de armazenamento provisório.

Como era esperado, os maiores valores de turbidez e cor aparente foram encontrados nos resultados das coletas efetuadas em dias de chuva precedidas por um período de estiagem mais prolongado. Nesta situação os valores destes parâmetros ficaram elevados nos primeiros $25 \mathrm{~L}$ e continuaram elevados durante todo o volume coletado nos seis galões de armazenamento provisório, não atendendo aos limites estabelecido pela NBR 15.527 (ABNT, 2007), que é de no máximo 5 UT, de acordo com as variações médias apresentadas nos gráficos das Figuras 4 e 5.

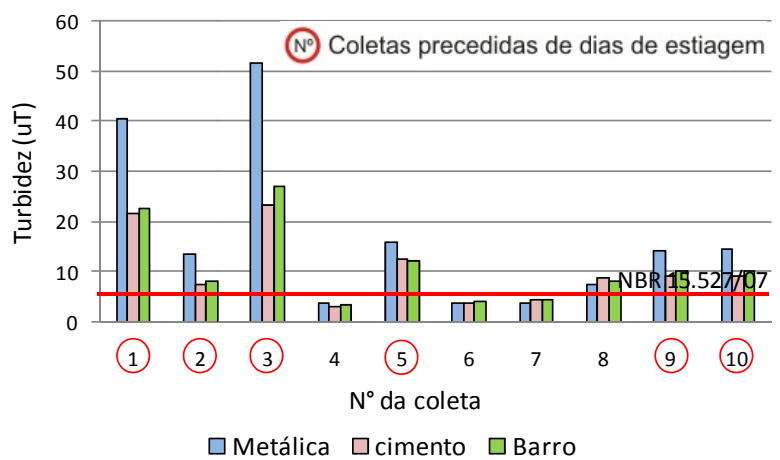

Figura 4: Variação média da turbidez ao longo das dez coletas efetuadas.

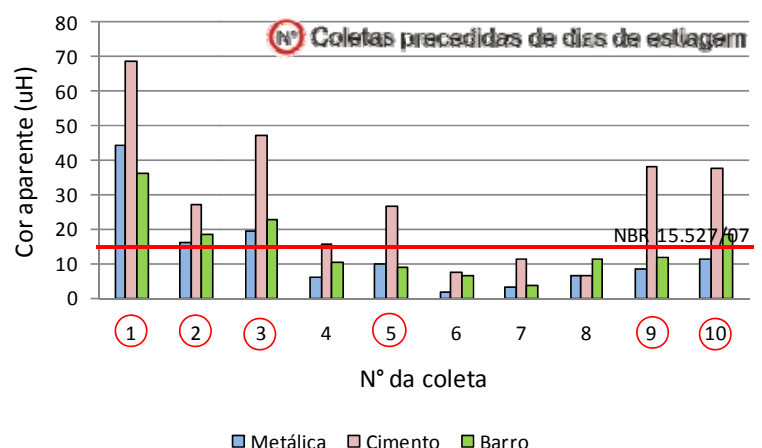

Figura 5: Variação média da cor aparente ao longo das dez coletas efetuadas. 
A Tabela 2 apresenta os resultados da qualidade de água para cada um dos três tipos de cobertura para os parâmetros turbidez e cor aparente, dentro dos padrões estabelecidos pela NBR 15.527 (ABNT, 2007), representados pelos quadros coloridos em azul e rosa, respectivamente. A área em destaque apresenta os resultados tanto de turbidez quanto de cor aparente dentro do estabelecido pela referida norma, determinando diferentes volumes de descarte em diferentes situações, para os três tipos de cobertura estudados.

Observando a Tabela 2, pode-se dizer que para a cobertura em telhas metálicas estudada, é necessário o descarte de 100 litros de água precipitada, equivalente a 1,33 $\mathrm{mm}$ de chuva acumulada, em qualquer evento de precipitação, desde que sejam descartados os primeiros eventos de chuva, ocorridos para esta localidade em Goiânia, entre os meses de setembro e outubro, o que deve ocorrer para qualquer uma das três coberturas estudadas.

Para a cobertura em telhas de cimento amianto, é necessário o descarte de 25 litros de água precipitada, equivalente a $0,33 \mathrm{~mm}$ de água de chuva acumulada, desde que as coletas sejam precedidas de períodos chuvosos.

Para a cobertura em telhas de barro é necessário o descarte de 150 litros de água precipitada, equivalente a $2 \mathrm{~mm}$ de chuva acumulada, para todos os eventos de precipitação ocorridos, pois a água não apresentou qualidade dentro dos padrões estabelecidos pela NBR 15.527 (ABNT, 2007), em eventos de coletas precedidas por períodos chuvosos como o ocorrido com a cobertura em telhas de cimento amianto.

\section{Legenda}

TURBIDEZ COR APARENTE

ÁGUA COM QUALIDADE PARA TURBIDEZ E COR APARENTE DENTRO DO PADRÕES ESTABELECIDOS PELA NBR 15.527/07

\begin{tabular}{|c|c|c|c|c|c|c|c|c|c|c|}
\hline$N^{\circ}$ DA COLETA & 01 & 02 & 03 & 04 & 05 & 06 & 07 & 08 & 09 & 10 \\
\hline GALÕES & & & & & & & & & & \\
\hline \multicolumn{11}{|c|}{ COBERTURA EM TELHAS METÁLICAS } \\
\hline \multicolumn{11}{|l|}{ M1 } \\
\hline \multicolumn{11}{|l|}{ M2 } \\
\hline \multicolumn{11}{|l|}{ M3 } \\
\hline \multicolumn{11}{|l|}{ M4 } \\
\hline \multicolumn{11}{|l|}{ M5 } \\
\hline \multicolumn{11}{|l|}{ M6 } \\
\hline \multicolumn{11}{|c|}{ COBERTURA EM TELHAS DE CIMENTO AMIANTO } \\
\hline \multicolumn{11}{|l|}{ C1 } \\
\hline \multicolumn{11}{|l|}{$\mathrm{C2}$} \\
\hline \multicolumn{11}{|l|}{ C3 } \\
\hline \multicolumn{11}{|l|}{ C4 } \\
\hline \multicolumn{11}{|l|}{ C5 } \\
\hline \multicolumn{11}{|l|}{ C6 } \\
\hline \multicolumn{11}{|c|}{ COBERTURA EM TELHAS DE BARRO } \\
\hline \multicolumn{11}{|l|}{ B1 } \\
\hline \multicolumn{11}{|l|}{ B2 } \\
\hline \multicolumn{11}{|l|}{ B3 } \\
\hline \multicolumn{11}{|l|}{ B4 } \\
\hline \multicolumn{11}{|l|}{ B5 } \\
\hline B6 & & & & & & & & & & \\
\hline
\end{tabular}

\subsubsection{Condutividade e sólidos dissolvidos}

Os maiores valores de condutividade e sólidos dissolvidos observados nos resultados foram obtidos quando as coletas ocorreram em dias de chuva precedidas por um período seco, como pode ser visto nos gráficos das Figuras 6 e 7. 


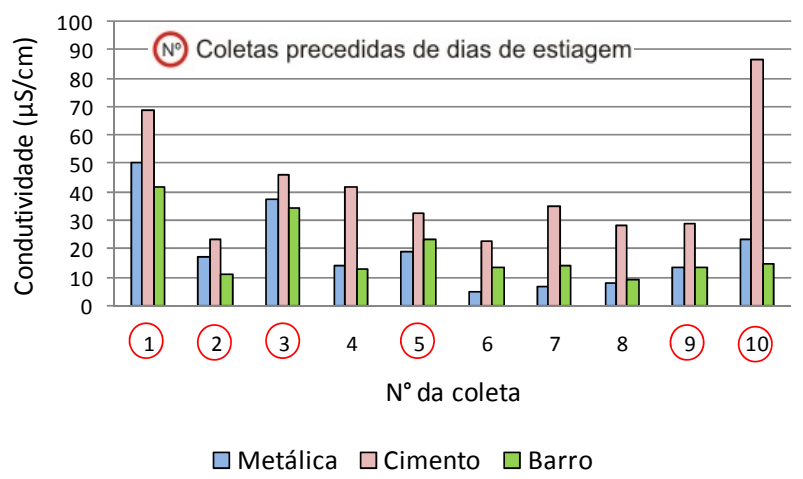

Figura 6: Variação média de condutividade ao longo das dez coletas efetuadas.

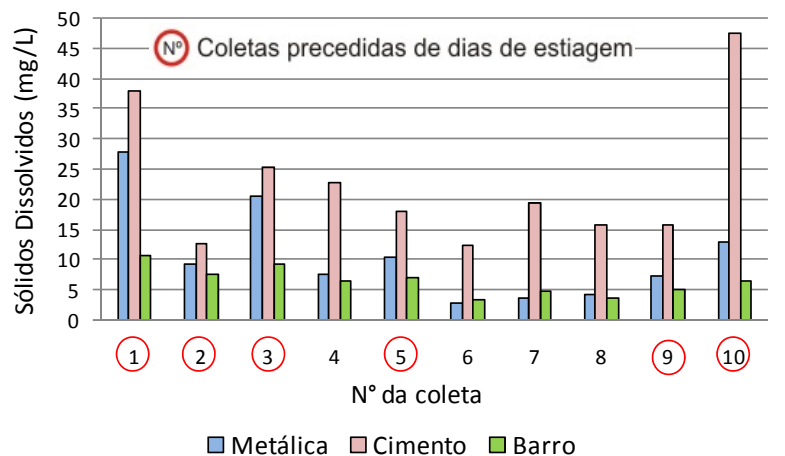

Figura 7: Variação média de sólidos dissolvidos ao longo das dez coletas efetuadas.

A condutividade é um parâmetro importante na medida da poluição ao determinar a quantidade de sais dissolvidos na água. A NBR 15.527 (ABNT, 2007), não estabelece limite de valor deste parâmetro ou do parâmetro sólidos dissolvidos, para que a água utilizada ofereça qualidade para consumo.

A variação ocorrida nos resultados de sólidos dissolvidos em cada tipo de cobertura é semelhante à variação encontrada nos resultados de análises de condutividade, por serem estes parâmetros, diretamente proporcionais. Yaziz et al. (1989), em seu experimento, demonstrou que nas amostras coletadas, no primeiro fluxo de água, a concentração de poluentes foi grande, mas que diminuíram nas amostras subsequentes.

\subsubsection{Alcalinidade e dureza}

A alcalinidade e a dureza são parâmetros que apresentaram diferenças significativas de um tipo de cobertura para outro com elevadas diferenças nos valores dos resultados, apresentados nos gráficos das Figuras 8 e 9.

Os resultados das análises para alcalinidade e dureza das amostras da cobertura em telhas de cimento amianto, como era previsível, ficaram mais elevados do que os outros tipos de cobertura, estando seus valores entre 7 e $46 \mathrm{mg} / \mathrm{L} \mathrm{CaCO}_{3}$, sendo que $8 \%$ de todos os resultados obtidos ficaram abaixo de $10 \mathrm{mg} / \mathrm{L}$ $\mathrm{CaCO}_{3}$. O material que constitui esta cobertura propicia o aumento da alcalinidade tendo ainda como influência o tempo de estiagem que antecedeu cada coleta.

Não foi verificada uma relação acentuada entre os resultados obtidos e o tempo de estiagem que antecedeu cada coleta, podendo ser observada uma sutil relação entre o período de estiagem e os resultados das análises obtidas das águas escoadas das coberturas em telhas metálicas e telhas de barro.

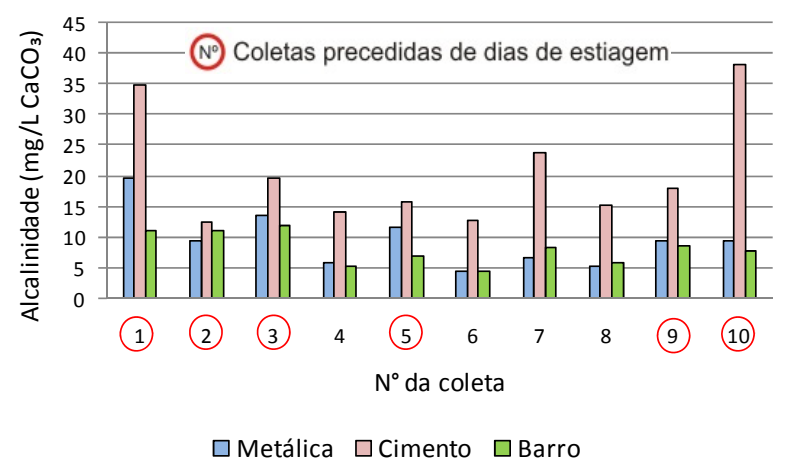

Figura 8: Variação média de alcalinidade ao longo das dez coletas efetuadas.

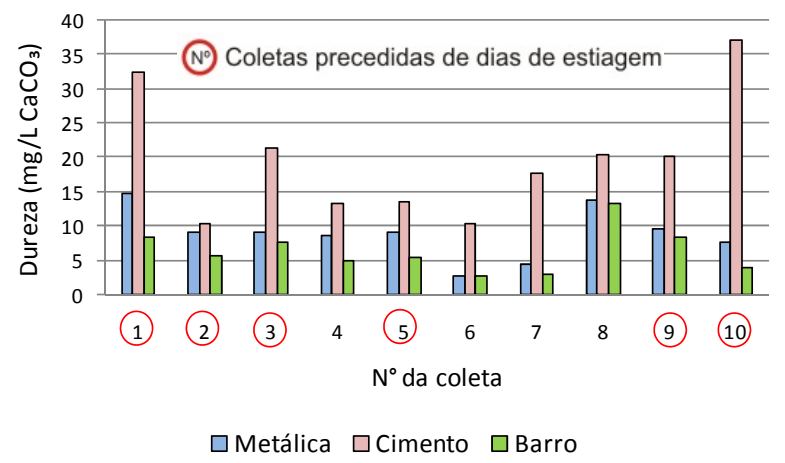

Figura 9: Variação média de dureza ao longo das dez coletas efetuadas.

\subsection{4 $\mathrm{pH}$ e ferro}

De acordo com o gráfico da Figura 10 observa-se que os valores médios de $\mathrm{pH}$ estiveram dentro da faixa estabelecida pela NBR 15.527 (ABNT, 2007).

Os maiores valor para $\mathrm{pH}$ foram encontrados em amostra da cobertura metálica com valor de 8,31, assim como o valor de 5,48 que foi o menor valor encontrado também na cobertura em telhas metálicas.

Foram encontrados três valores acima da faixa estabelecida pela Norma, para a cobertura em telhas de cimento amianto, porém bem próximos do limite superior estabelecido.

Para a cobertura em telhas de barro todos os valores de $\mathrm{pH}$ estiveram dentro da faixa estabelecida pela NBR 15.527 (ABNT, 2007). 
O ferro total não tem valor estabelecido na NBR 15.527 (ABNT, 2007), para que sua utilização para consumo seja aceita. É recomendável a concentração máxima de $0,3 \mathrm{mg} / \mathrm{L}$, sugerindo-se concentrações inferiores a $0,5 \mathrm{mg} / \mathrm{L}$, pois acima disso a água fica com sabor desagradável. Os valores de ferro total nas coberturas variaram de uma coleta para outra, conforme gráfico da Figura 11.

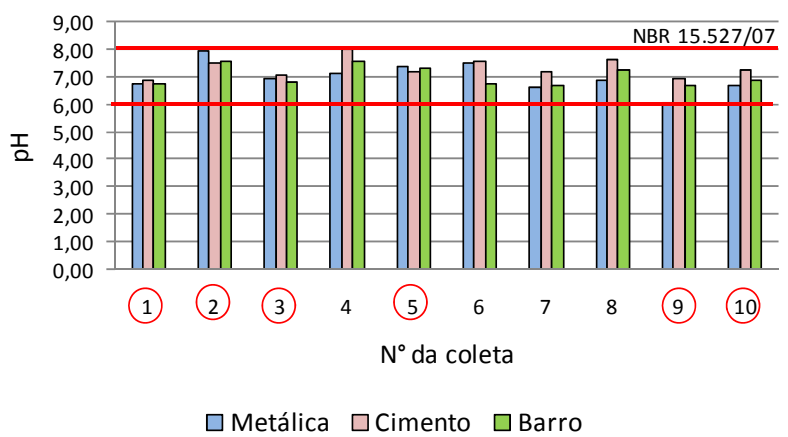

Figura 10: Variação média de pH ao longo das dez coletas efetuadas.

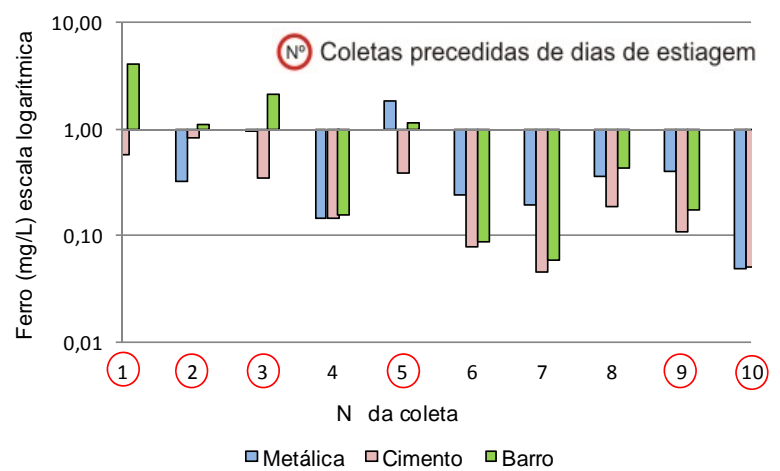

Figura 11: Variação média de ferro ao longo das dez coletas efetuadas.

O último galão de armazenamento provisório da cobertura em telhas metálicas apresentou resultados $20 \%$ acima do estabelecido como recomendável assim como os dois pontos da bombona de armazenamento que apresentaram valores $5 \%$ acima.

Os resultados para ferro total na cobertura de telhas de cimento amianto apresentaram-se $18 \%$ acima do estabelecido como recomendável.

A cobertura de telhas de barro apresentou os valores dos resultados mais elevados dentre os três tipos de cobertura. Pressupõe-se que seja causado pelo material da telha cuja composição é de solo tipo latossolo rico em ferro. Com o passar do tempo, a telha de barro se torna mais porosa e desprende com mais facilidade o material constituinte.

\subsubsection{Coliformes totais e E. coli}

Os coliformes totais e E. coli estiveram presentes em todas as amostras coletadas, assim como nos experimentos de Tordo (2004), Jaques (2005), May ( 2004), Coombes et al (2000) e Yaziz et al.(1989). As coletas de amostras foram obtidas dos galões de armazenamento provisório 1 e 6 e dos dois pontos de coleta R1 e R2 da bombona de armazenamento.

Não foi observada uma relação entre o período de estiagem e os valores encontrados para nenhum tipo de cobertura.

\subsubsection{Zinco e chumbo}

Foram efetuadas análises de zinco e chumbo para a última coleta ocorrida no dia 10 de fevereiro de 2010, nos Laboratórios da Aqualit, Tecnologia em Saneamento S.S. Ltda.

A análise foi efetuada para a água coletada do galão de armazenamento provisório 6, por ser o último reservatório de armazenamento de descarte já que o volume subsequente foi para o armazenamento.

O propósito destas análises é devido ao material constituinte das calhas que são em zinco e que estavam colocadas para a coleta de toda a água de chuva nos três tipos de cobertura e ainda devido ao material da pintura das telhas metálicas que poderiam ou não, conter uma quantidade de chumbo acima do recomendado.

Verificou-se, que os resultados ficaram de acordo com o estabelecido pela Resolução CONAMA № 357/2005 (classe 2). A NBR 15.527 (ABNT, 2007) não estabelece limites para estes parâmetros.

\section{CONCLUSÕES}

Como era esperado, verificou-se que períodos prolongados de estiagem proporcionam na água de chuva escoada sobre superfícies de telhados, um aumento nos valores de parâmetros como: turbidez, cor aparente, condutividade, sólidos dissolvidos e alcalinidade. Supõe-se que este fenômeno ocorra devido ao aumento do acúmulo de matéria orgânica e outros poluentes sobre as superfícies das coberturas.

Esta pesquisa possibilitou concluir que mesmo com a utilização de um sistema de descarte de águas de chuva, é necessário que sejam desprezadas as primeiras precipitações, no início do período chuvoso, que em Goiás ocorre de setembro e continua até outubro, para que se obtenha água com melhor qualidade para utilização e para a manutenção dos sistemas hidráulicos prediais.

Verificou-se que o armazenamento das águas coletadas após o devido descarte propicia a diminuição de valores de turbidez e cor aparente, promovida por meio da sedimentação. 
Observou-se a presença de coliformes totais e E coli nas amostras coletadas em todos os galões de armazenamento provisório e nas bombonas de armazenamento, demonstrando que a água não tem qualidade para aproveitamento humano mesmo para uso não potável, sendo necessária a incorporação de unidades de tratamento nos sistemas de aproveitamento de água de chuva.

O descarte por tempo conforme sugere algumas bibliografias não se mostrou adequado, para garantir a obtenção de água com qualidade assegurada, pois após um evento de precipitação com baixa intensidade, a água coletada apresenta-se com qualidade mais baixa.

\section{AGRADECIMENTOS}

Esta pesquisa contou com o apoio financeiro e institucional das seguintes entidades: Agência Nacional de Águas - ANA, Saneamento de Goiás S/A - SANEAGO, Secretaria das Cidades do Estado de Goiás, Universidade Federal de Goiás - UFG e Tigre S/A.

\section{REFERÊNCIAS BIBLIOGRÁFICAS}

APHA; AWWA; WEF. Standard methods for the examination of water and Wastewater. $21 \mathrm{Ed}$. Washington D.C., EUA, 2004.

\section{ASSOCIAÇÃO BRASILEIRA DE NORMAS TÉCNICAS. NBR} 15.527: Água de chuva - Aproveitamento de cobertura em áreas urbanas para fins não potáveis - Requisitos, 2007.

BRASIL. Ministério da Saúde. Portaria n. 518, de 25 de março de 2004: Estabelece os procedimentos e responsabilidades relativos ao controle e vigilância da qualidade da água para consumo humano e seu padrão de potabilidade e dá outras providências. Diário Oficial da União, n. 59, 26/03/2004, p. 266-270.

JAQUES, R.C. Qualidade da água de chuva no município de Florianópolis e sua potencialidade para aproveitamento em edificações. Dissertação (Mestrado). Engenharia Ambiental da Universidade Federal de Santa Catarina, Florianópolis, SC, 2005.

MAY, S. Estudo da Viabilidade do Aproveitamento de Água de Chuva para Consumo Não Potável em Edificações. Dissertação (Mestrado). Engenharia Civil. Escola Politécnica da Universidade de São Paulo. São Paulo, SP, 2004.
McKinsey. World Economic Forum: Reneewable Water Resources - Water Economics Team, 2009.

CONSELHO NACIONAL DO MEIO AMBIENTE - CONAMA, Resolução n $^{\circ}$ 357, de 17 de março de 2005, Dispõe sobre a classificação dos corpos de água e diretrizes ambientais para o seu enquadramento, bem como estabelece as condições e padrões de lançamento de efluentes, e dá outras providências. 2005.

COOMBES, P.J., KUCZERA, G., KALMA, J.D. Rainwater quality from roofs, tanks and hot water systems at Figtree Place. In: $3^{\circ}$ International Hydrology and Water Resources Symposium of The Institution of Engineers. Hydro 2000. Proceedings v.1 Perth, Australia 20-23 nov, 2000.

TORDO, O.C., Caracterização e avaliação do uso de águas de chuva para fins potáveis. Dissertação (Mestrado) Centro de Ciências Tecnológicas da Universidade Regional de Blumenau, FURB, SC, 2004.

YAZIZ, M., GUNTING, H., SAPIARI, N., \& GHAZALI, A. Variation in rainwater quality from roof catchments, Water Research, v. 23(6), p.761-5, 1989. 